\title{
PEDAGOGIAS DA NOITE: EXPERIÊNCIAS E SENSAÇÕES COLETIVAS EM UM PARQUE PÚBLICO
}

\author{
Eloenes Lima da SILVA ${ }^{1}$
}

\begin{abstract}
Resumo
O artigo tem por objetivo dar visibilidade a modos pedagógicos de viver na noite mediante a identificação de experiências coletivas durante um evento noturno no maior parque público da cidade de Porto Alegre, Brasil. A primeira parte do texto propõe articulações entre os conceitos de "pedagogia”, "experiência” e "lugar” a partir da perspectiva teórica de "espaço-tempo”. Em seguida são destacados os caminhos metodológicos utilizados durante a pesquisa. Na terceira parte, a música executada ao vivo, as produções artesanais, os “abraços grátis” e outras intervenções são analisadas por meio da apresentação de "cenas noturnas”. Os resultados apontam que os encontros, os convívios, as aproximações e trocas sociais são experiências vividas através de sensações em comum em que os afetos, a segurança, o "estar junto" funcionam como pedagogias, orientando e conduzindo os sujeitos em lugares noturnos da cidade.
\end{abstract}

Palavras-chave: Educação. Pedagogias. Experiência. Espaço público. Lugar.

\footnotetext{
${ }^{1}$ Doutor e mestre em Educação. Secretaria Estadual de Educação, RS, Brasil. ORCID: https://orcid.org/0000-0003-0614-0218.

Email: eloenessilva@gmail.com.
} 


\title{
PEDAGOGIES OF THE NIGHT: EXPERIENCES AND COLLECTIVE SENSATIONS IN A PUBLIC PARK
}

Eloenes Lima da SILVA

\begin{abstract}
The article aims to give visibility to pedagogical ways of living at night by identifying collective experiences during an evening event in the largest public park in the city of Porto Alegre, Brazil. The first part of the text proposes articulations between the concepts of "pedagogy", "experience" and "place" from the theoretical perspective of "space-time". Next, the methodological paths used during the research are highlighted. In the third part, music performed live, artisanal productions, "free hugs" and other interventions are analyzed through the presentation of "night scenes". The results point out that the meetings, the get-togethers, the approximations and social exchanges are experiences lived through common sensations in which affections, security, "being together" work as pedagogies, guiding the subjects in night places in the city.
\end{abstract}

Keywords: Education. Pedagogies. Experience. Public space. Place. 


\title{
PEDAGOGÍAS DE LA NOCHE: EXPERIENCIAS Y SENSACIONES COLECTIVAS EN UN PARQUE PÚBLICO
}

Eloenes Lima da SILVA

\begin{abstract}
Resumen
Este artículo tiene por objetivo dar visibilidad a los modos pedagógicos de vivir en la noche mediante la identificación de experiencias colectivas durante un evento nocturno en el mayor parque público de la ciudad de Porto Alegre, Brasil. En la primera parte del texto se propone articulaciones entre los conceptos de "Pedagogía”, "Experiencia” y "lugar", partiendo de la perspectiva teórica de "espacio-tiempo". Enseguida, son destacados los caminos metodológicos utilizados durante la pesquisa. En la tercera parte, la música ejecutada en directo, las producciones artesanales, los "abrazos gratis" y otras intervenciones son analizadas por medio de la presentación de "escenas nocturnas". Los resultados apuntan que los encuentros, los convivios, las aproximaciones e intercambios sociales son experiencias vividas a través de sensaciones en común en que los afectos, la seguridad, el acto de "estar junto" funcionan como pedagogías, orientando y conduciendo los sujetos en lugares nocturnos de la ciudad.
\end{abstract}

Palabras clave: Educación. Pedagogía. Experiencia. Espacio público. Lugar. 


\section{Introdução}

Noite de sexta feira. Dirijo-me ao local conhecido como Parque Farroupilha ou Redenção, na região central da cidade de Porto Alegre. O motivo: a realização do evento Serenata Iluminada. Chego ao local e percebo centenas de ocupantes, jovens em sua maioria, sentados e deitados na grama ou flanando pelo parque, onde conversam, beijam, abraçam, cantam, tocam, dançam e recitam poesias em saraus improvisados ao ar livre. Bebidas, comidas e outros produtos artesanais são comercializados, aumentando a interação entre os participantes. Corpos, imagens, cheiros, sons e luzes misturam-se naquele espaço-tempo público noturno. Um lugar de inúmeras sensações, um lugar de múltiplas experiências. (Noturnos de Campo) ${ }^{2}$

O excerto destacado na abertura do texto refere-se ao evento conhecido como Serenata Iluminada, realizado periodicamente no Parque Farroupilha em Porto Alegre, Brasil. Conhecido como Campos da Redenção, o parque recebeu esse nome em homenagem à precoce abolição da escravatura que ocorreu na cidade em 1884. Em 1935, foi denominado como Parque Farroupilha, por ocasião do centenário da Revolução Farroupilha (FRANCO, 2006). Nos anos de 1970 até meados de 1980, um relativo abandono tomou conta do parque, situação paulatinamente revertida com a implantação da feira de artesanato, arte e antiguidades que ocorre aos domingos, conhecida como Brique da Redenção. Ao entrar no século XXI, o Parque Farroupilha, principalmente durante a noite, passa a ser marcado pela insegurança e pelo consequente esvaziamento do seu espaço público, enfraquecendo, com isso, seu potencial como espaço de lazer.

Se por um lado a insegurança, a violência e o medo são condições problemáticas que resultam no abandono de muitos espaços das metrópoles, por outro, a possibilidade de relações sociais por meio dos convívios, dos encontros, dos relacionamentos e demais formas de interação e trocas sociais em um lugar urbano e público podem se configurar como experiências coletivas vividas em um parque à noite. O evento Serenata Iluminada surge com o propósito de “ocupação dos espaços públicos da cidade em prol de mais segurança, do direito à cidade, para que todos possam compartilhar os parques, as ruas com os amigos, vizinhos, familiares, enfim, com todas as pessoas também à noite”3. Iniciativas como essa, além de recuperarem a convivência e conterem o esvaziamento dos espaços públicos noturnos, procuram reverter ideias de que a cidade quase sempre apresentou de uma existência alternada pela sucessão dia-noite na qual o período noturno foi, por muito tempo, considerado como um horário de repouso social e voltado para dentro da esfera privada.

Como aponta Gwiazdzinski (2014), é à noite que outra cidade entra em cena, com suas luzes, sua decoração, seus novos atores, suas práticas e seus modos de vida característicos. A noite pode

\footnotetext{
${ }^{2}$ Denomino como Noturnos de Campo, as anotações registradas durante as saídas investigativas à noite em diferentes lugares públicos da cidade de Porto Alegre, Brasil.

${ }^{3}$ Retirado de: https://www.facebook.com/pg/SerenataIluminada/about/?ref=page_internal.
} 
funcionar como lugar de refúgio, pois nela, como afirma Margulis (2005), os sujeitos encontram a ilusão de liberdade e de desvinculação das regras e normas sociais impostas pelo dia. A noite, para o autor (2005), ressignifica a cidade, o espaço e o tempo, pois proporciona a sensação de não mais estarmos colonizados ou controlados pelos poderes regidos pelo regime diurno. A noite urbana expõe uma diversidade sociocultural que integra lugares e sujeitos, produzindo uma multiplicidade de situações, condições e possibilidades. E isso pode ser identificado desde os aspectos materiais, como os espaços físicos e arquitetônicos de uma cidade, até aqueles imateriais, como a produção de outras subjetividades, e que são produzidas a partir das inúmeras relações estabelecidas por meio das vivências na noite da cidade (ALMEIDA e TRACY, 2003). São muitos os modos de vida pública urbana que enriquecem os saberes, as práticas e as experiências na vida noturna (MAFFESOLI, 2003, 2004).

Ellsworth (2005) considera as experiências vivenciadas em diferentes espaços e tempos da cidade como construtoras de sensações por meio de redes que movimentam inúmeras interações entre corpo, mente e cérebro. Segundo a autora (2005), é preciso romper o entendimento de que o indivíduo pensa, age e sente separadamente, e isso é crucial para a produção de experiências. Uma vez que estão implicadas com o que é praticado, pensado e sentido, essas experiências dizem respeito a tudo o que é vivido, possuindo uma "força pedagógica”, permitindo dar visibilidade às dinâmicas das múltiplas pedagogias que são colocadas em ação por meio dos “diálogos” incessantes entre os sujeitos e o mundo que os cerca.

É importante salientar que, assim como os processos educativos podem ser encontrados em uma diversidade de locais, do mesmo modo, as pedagogias são entendidas aqui em sua pluralidade de formas e atuações. Segundo Giroux e Mclaren (1995), existe pedagogia em qualquer lugar em que o conhecimento é produzido ou em qualquer ambiente em que seja possível traduzir as experiências sociais. Encontrando-se em todos os lugares, as pedagogias estão implicadas com práticas cotidianas, operando através de um emaranhado de relações espaciais e temporais, compostas de atores humanos e não humanos como objetos e arquiteturas e pelas quais aprendemos a moldar capacidades, hábitos e comportamentos (WATKINS, NOBLE E DRISCOLL, 2015). Para Camozzato e Costa (2013, p. 23), a pluralização das pedagogias no tempo presente pode ser entendida como "uma marca da contínua vontade de investir e atuar sobre todos os aspectos e âmbitos da vida dos sujeitos contemporâneos - o que faz de cada um de nós um agente de incessante transformação e atuação com os saberes”. Desse modo, entendidas para além de seus 
formatos institucionais e da configuração de normas e regras prescritivas, as pedagogias estão vinculadas às experiências mais cotidianas dos sujeitos.

A partir das argumentações expostas, este artigo tem por objetivo dar visibilidade a modos pedagógicos de viver na noite, mediante a identificação de experiências coletivas durante um evento noturno em um parque público da cidade. Para tanto, o texto analisa diferentes intervenções realizadas durante uma das edições do evento Serenata Iluminada, realizada no maior parque público da cidade de Porto Alegre, Brasil. A primeira parte do texto propõe articulações entre os conceitos de "pedagogia”, de "experiência” e de "lugar” a partir da perspectiva teórica de "espaçotempo” como dimensão pública na noite da cidade. Em seguida, são destacados os caminhos metodológicos utilizados durante a pesquisa. Na terceira parte, a produção empírica é exposta por meio de "cenas noturnas" compostas pela escolha dos lugares a serem investigados, das observações, abordagens e registro das práticas, bem como dos relatos e anotações feitas em campo. Vale salientar que o procedimento de organização e montagem das cenas noturnas se constituiu em um importante passo metodológico de pesquisa, permitindo elaborar reflexões mais precisas na condução das discussões analíticas. Os resultados apontam que os encontros, os convívios, as aproximações e trocas sociais são experiências vividas em comum implicadas com modos de condução em que os afetos, a segurança, o “estar junto” funcionam como pedagogias, orientando e conduzindo os sujeitos em um lugar noturno da cidade.

\section{Adentrando o espaço-tempo noturno: experiência e sensação como modos pedagógicos de viver em lugares públicos}

As intervenções noturnas realizadas no Parque Farroupilha durante o evento Serenata Iluminada produziram experiências que possibilitaram outras formas de viver à noite, a partir da interação dos sujeitos entre si e com aquele lugar. Experiências que se afastaram das sensações preenchidas pela aridez dos dias e pelo ritmo veloz e fugaz que a cotidianidade urbana proporciona. E como essas experiências estão implicadas com formas pedagógicas de viver em diferentes lugares no espaço-tempo da noite na cidade?

A expressão “espaço-tempo” é utilizada aqui em busca de ampliar a ideia pela qual os sujeitos compreendem o seu mundo e sua existência através da posição que ocupam no espaço e na forma como conduzem, produzem e organizam o seu tempo. Para Harvey (2008), uma ruptura cultural com as características progressistas e positivistas oriundas da modernidade colocou em questão o sentido do espaço e do tempo em um mundo instável e onde os horizontes estão em rápida 
expansão. Conforme o autor (2008), a certeza de um espaço e de um tempo absolutos foi abalada e “substituída pelas inseguranças de um espaço relativo em mudança, em que os eventos de um lugar podiam ter efeitos imediatos e ramificadores sobre vários outros” (p. 239).

Diferente do espaço absoluto, fixo e delimitado, do espaço da individuação, da propriedade e da territorialidade onde planejamos nossos eventos, o espaço relativo abre possibilidades de escolher múltiplas geometrias e de ser relativizado desde o ponto de vista do observador (HARVEY, 2012). Para o autor (2012), enquanto o caráter único do espaço absoluto define localizações e individualizações, o espaço relativo pode criar mapas distintos, diferenciando e visualizando distâncias, e até interrompendo-as com nossas paradas e alternâncias de trajeto, bem como criar redes e relações topológicas. Desse modo, Harvey considera impossível separar o espaço do tempo, denominando essas duas dimensões como espaço-tempo ou espaço-temporalidade.

Se o espaço-tempo possibilita a criação de distintas redes de relações materiais, e imateriais, entre os sujeitos e o mundo em que vivem, o conceito de topofilia, criado por Yi-Fu Tuan (1980), adquire importância nessa discussão, pois engloba "todos os laços afetivos dos seres humanos com o meio ambiente material” (p. 107). Para Tuan, o espaço transforma-se em lugar, em topos, à medida que adquire definição e significado cotidianos. O lugar representa uma pausa nos movimentos, é sutil e possuidor de modos de expressão basicamente estéticos, podendo variar do efêmero ao "prazer que se tem de uma vista, até a sensação de beleza, igualmente fugaz, mas muito mais intensa, que é subitamente revelada” (TUAN, 1980, p. 107). À apreciação de um cenário em um ambiente, à experiência estética em um lugar, somos apanhados quase sempre de surpresa, sentimos um contato repentino com o desconhecido na realidade em que estamos inseridos.

Desde Locke (1999), temos conhecimento de que as ideias de “sensações” são provenientes dos sentidos em contato com o exterior, enquanto que as de "reflexão" se originam no interior do indivíduo. A simultaneidade entre essas duas ideias geraria as de existência, de duração, de tempo e de espaço como “experiências sensíveis” produzidas por meio dessa interação do indivíduo com as condições exteriores encontradas no meio (LOCKE, 1999). Sob outra perspectiva, Deleuze (1981) aponta na mesma direção ao afirmar que "a sensação tem uma face voltada para o sujeito (o sistema nervoso, o movimento vital, o “instinto”, o “temperamento” [...]), e a outra face voltada para o objeto (o “fato”, o lugar, o acontecimento)” (p.19). E, continua o autor (1981), a sensação “[...] pode ser as duas coisas indissoluvelmente, ser o estar-no-mundo como dizem os fenomenologistas: eu me torno na sensação e alguma coisa me acontece pela sensação, um pelo outro, um no outro” (p.19). 
No texto A Obra de Arte na Era de sua Reprodutibilidade Técnica, Benjamin (2012) já salientava que os aspectos físicos como a arquitetura de uma cidade possuem formas de recepção que ativam outras formas de percepção em seus habitantes. Escreve Benjamin:

Os edifícios comportam uma dupla forma de recepção: pelo uso e pela percepção. Em outras palavras: por meios táteis e óticos. [...]Pois não existe nada na recepção tátil que corresponda ao que a contemplação representa na recepção ótica. A recepção tátil se efetua menos pela atenção que pelo hábito. No que diz respeito à arquitetura, o hábito determina em grande medida a recepção ótica. Pois as tarefas impostas ao aparelho perceptivo do homem, em momentos históricos decisivos, são insolúveis na perspectiva puramente ótica pela contemplação. Elas se tornam realizáveis gradualmente, pela recepção tátil, através do hábito (BENJAMIN, 2012. p. 209).

As argumentações de Benjamin, escritas nos anos de 1940, destacam as possibilidades de aumento da percepção dos habitantes urbanos por meio da interação com as condições e situações exteriores, como a arquitetura das cidades. A percepção através do toque e da visão, mas também dos outros sentidos, são ativadores de sensações que proporcionam distintas experiências vividas em contato com os diferentes lugares, com os diversos topos de uma cidade.

Em sua obra Places of Learning: Media, Architecture, Pedagogy, Ellsworth (2005) coloca em evidência o caráter pedagógico da ida social contemporânea, ressaltando como experiências podem ocorrer em lugares da cidade. Para tanto, Ellsworth (2005) busca identificar a "força pedagógica" atuante em diversos locais classificados e denominados por ela como “lugares de aprendizagem”. Lugares onde somos movidos através do tempo e do espaço, entre conhecer e não conhecer; no espaço e no tempo de aprendizagem como uma experiência vivida, como abertura e intervalo de mudança para um futuro imprevisível. Segundo a autora (2005), identificar um lugar pressupõe um foco nos significados e nas condições que determinados ambientes, comportamentos ou eventos apresentam para a produção de distintas experiências de aprendizagem. Se olharmos para esses lugares como possibilidades para multiplicar as potencialidades da aprendizagem, a sua força como pedagogia se torna mais aparente (ELLSWORTH, 2005).

Ellsworth (2005) afirma que o encontro de diferentes indivíduos ou grupos em um mesmo lugar é indispensável para a pedagogia, pois são os movimentos e sensações em interação entre corpo/mente/cérebro que articulam o "exterior" e o “interior” como experiências vividas nesse emaranhado entre o eu, o outro e o mundo. Para a autora, uma experiência é plenamente vivida através da permanente exposição e interação com as condições do lugar e com o outro que ali também se encontre. Segundo Ellsworth (2005), vivemos uma experiência por meio do encontro com os aspectos objetivos, com a exterioridade do mundo e do “outro”, e os processos subjetivos emergentes a partir dessa relação. 
Ao possibilitar tais conexões, esses movimentos funcionam, segundo Ellsworth (2005), como uma “dobradiça pedagógica”, pois eles colocam em articulação tudo que nos é exterior e a forma como "interiorizamos" e operamos sobre nós mesmos. Segundo a mesma autora (2005), as experiências produzidas nesses encontros são sempre interativas, provocativas pois, se reside aí alguma intenção pedagógica, ela está emaranhada em ritmos, intensidades e durações que movimentam o corpo e a mente como uma unidade para as sensações que são produzidas por meio desse encontro. Ademais, é preciso lembrar que as experiências produzidas a partir de tais conexões são sempre inacabadas, estão em constante devir.

As experiências vivenciadas a partir desses entrelaçamentos, dessas intervenções pelas quais a percepção é ativada através dos sentidos, são imprevisíveis. Larrosa (2002, p.21) nos ajuda a entender essas dimensões não como experiências exteriores que passam e acontecem apenas fora de nós, mas como "o que nos passa, o que nos acontece, o que nos toca”, deixando em nós o que pode ser considerado uma “experiência/sentido”. Essa experiência sensível que nos atravessa, cria realidades, funciona como potente mecanismo de subjetivação, atuando no "[...] modo como nos colocamos diante de nós mesmos, diante dos outros e diante do mundo em que vivemos" (LARROSA, 2002, p. 21). Essas podem ser experiências sensíveis enquanto realidade empírica, uma vez que, como destaca Maffesoli (2010), permitem “o desenvolvimento do sentido estético em suas formas artísticas clássicas ou em suas formas cotidianas” (p.67).

A partir das proposições dos autores, inferimos que a noite das cidades contemporâneas pode ser entendida como um espaço-tempo onde uma multiplicidade de experiências individuais e coletivas são vividas, posto que estão envolvidas com a participação e a convivência entre sujeitos. Ao produzir, e também ser produzido pelas inúmeras condições e situações daqueles que o habitam e o ocupam, o espaço-tempo da noite apresenta e possibilita a identificação de determinados lugares noturnos e públicos com características próprias que proporcionam distintos modos de agir, pensar e sentir.

Ainda que sob diferentes perspectivas teóricas, o que tais autores enfatizam são os movimentos que colocam em interação o “exterior”, a objetividade dos espaços físicos, e a capacidade "interior” ou subjetiva dos seres humanos de modelar e remodelar percepções, práticas, reflexões e pensamentos, atuando simultaneamente com os sentidos orgânicos do corpo. Esses movimentos, como experiências produtoras de inúmeras sensações, são pedagógicos, pois colocam em ação nossas formas de agir, pensar e sentir em contato com o mundo e com os outros. Como identificar esses movimentos no maior parque público de uma cidade à noite? 


\section{Adentrado a noite da cidade: caminhos metodológicos}

Os dados expostos neste texto fazem parte de um corpus de pesquisa organizado entre os anos de 2014 a 2018. Para tanto, determinados lugares públicos na região central de Porto Alegre foram escolhidos para a investigação: além da extensão do Parque Farroupilha, onde foi realizado o referido evento, três viadutos localizados no Centro Histórico e duas ruas de frequência boêmia foram selecionados. Os recursos utilizados foram registros fotográficos e audiovisuais, abordagens, entrevistas e conversas informais com determinados sujeitos encontrados nos lugares selecionados. Cabe destacar que a pesquisa adotou aspectos qualitativos, estabelecendo uma relação particular entre sujeito-objeto, em que o pesquisador procurou observar e analisar os diferentes ambientes sociais em que sujeitos estão inseridos e como realizam suas práticas cotidianas (BAUER; AARTS, 2014).

A metodologia de pesquisa priorizou caminhadas noturnas ao estilo de um flâneur contemporâneo, em que o pesquisador adentrou o espaço-tempo da noite urbana em busca de investigar as experiências vividas em determinados lugares públicos. A pesquisa fez uso da técnica da “observação casual” (LORITE GARCÍA, 2000). Ao propor uma “observação casual” - e não casual observação - para estudar as transformações sociais e midiáticas em microterritorialidades cotidianas, o autor (2000) oferece alguns elementos interessantes que auxiliaram durante as investigações. Lorite Garcia salienta que a “observação casual” se inicia ao acaso, a partir da observação das “[...] mudanças efetivas que estão sendo produzidas [naquela] realidade” (p. 8), do que está sendo transformado pelas vivências em um lugar. Para o autor (2000), o tempo destinado à observação não é estabelecido previamente, a duração é definida enquanto o pesquisador se encontrar no local observado. A técnica da “observação casual” serviu como guia, sinalizando e conduzindo a atuação do pesquisador em campo.

\section{Compondo cenas noturnas em um parque público}

Ocupar um parque à noite por meio da música executada ao vivo, dos “abraços-grátis” e outras trocas sociais possibilitou transformá-lo em lugar propício para a produção das experiências e das sensações vividas de forma coletiva e pública. Durante a realização do evento Serenata Iluminada, o espaço-tempo do Parque Farroupilha distanciou-se de sua situação de habitual insegurança pública urbana e aproximou-se da condição de topofilia noturna. De acordo com Sennett (2008), no seio das transformações que remodelaram o desenho urbano no início do século XIX, os lugares públicos como ruas, praças e parques foram considerados os ambientes de 
excelência para a circulação da vida social que se acentuou na modernidade. Segundo o mesmo autor, desde antes do século XIX já existia uma crença burguesa de que, em público, "as pessoas experimentavam sensações e relações humanas que não poderiam ser experimentadas em qualquer outro cenário ou contexto social” (p. 39).

A montagem das “cenas noturnas” possibilitou maior organização para a realização das análises e a verificação da força pedagógica por meio das experiências vividas coletivamente durante o evento noturno Serenata Iluminada. O termo “cena”, do latim scena e do grego skené, é definido como "tenda”, "lugar de sombra”, “abrigo de madeira onde se vestem os atores", remetendo a um ambiente onde os indivíduos se transmutam em "personagens”. "Cena” também pode significar o "lugar onde se passa uma ação, cenário”; “paisagem, horizonte de visão”, ou ainda, "estar em cena, ser alvo de interesse, de comentários; estar em moda”.

Assim a composição de uma cena noturna envolveu desde um conjunto de práticas e de sujeitos, dos aspectos visuais e sonoros, bem como dos demais detalhes materiais e imateriais que coexistem de forma simultânea em um mesmo lugar. Componentes ordinários muitas vezes despercebidos, mas durante a pesquisa se tornaram indispensáveis para identificar as experiências vividas e mostrar a força pedagógica presente em um lugar noturno e público. As cenas noturnas apresentadas neste texto destacam aproximações, encontros e trocas sociais como experiências, como sensações implicadas com modos de condução e pelos quais o Parque Farroupilha funcionava como lugar de atuação para distintas pedagogias na noite.

\section{Cena 1 - Fundir-se com o outro: música ao vivo e leitura noturna à beira do lago}

Ao caminhar pelo parque, cenas inusitadas são observadas. Um participante realiza uma performática leitura na lateral do lago do parque, posicionando-se como um pensador introspectivo. Parece não se importar com os passantes em volta de si. Segue absorto... Mais adiante, músicos tocam e cantam em uma interação com o público que os rodeia, já que não possuem tablado ou qualquer outro palco que os destaque dos demais participantes do evento. $O$ som da música parece deslizar pelo ambiente, misturando-se com as velas, as luminárias e os outros tipos de iluminação artificial pendurada nas árvores, formando sombras bruxuleantes. Sons e luzes na noite chegam aos lugares mais escondidos do parque, misturam-se, atingindo indivíduos e grupos, movimentando seus corpos (Noturnos de Campo).

A observação durante o evento Serenata Iluminada não se constituiu somente pela materialidade das práticas realizadas, pois, mesmo que descritas e registradas fotograficamente em sua dimensão espaço-temporal, o que era "sentido" por meio da interação dos participantes entre si e com o lugar era quase impossível de captar. Sensações que pareciam não estabelecer separações entre 
"homem e mundo" em dois polos distintos, aproximando-se de experiências vividas integralmente, em que a ideia de inseparabilidade entre corpo/mente é crucial para seu entendimento.

Para Duarte Junior (2001), a visão de Descartes, ao separar em reinos independentes corpo e mente, fundou o entendimento do corpo como um intrincado mecanismo constituído de peças menores, cujo funcionamento se assemelharia a uma máquina ou relógio. Dessa concepção deriva a ideia de que, da análise exaustiva de suas partes, se pode chegar à compreensão de um todo, estando ainda esse mecanismo corporal excluído de qualquer interação como meio natural, social e cultural (DUARTE JUNIOR, 2001). Para o autor, a célebre e notória “dicotomia cartesiana” que estabeleceu as bases do conhecimento racional moderno, separando o corpo e a mente dos seres humanos reafirmou a prioridade desta em relação àquele.

No livro Notas sobre a Pós-Modernidade: O Lugar Faz o Elo, Maffesoli (2004) afirma que, através da fecundidade da sinergia entre espaço, tempo e as sociabilidades, existe a possibilidade “das pessoas sentirem e experimentarem em comum” (p. 48). Para Maffesoli (2004, p. 58), todas essas vivências sociais são celebradas, pois os espaços da metrópole são constituídos por diversos “altares”, lugares que fazem o elo e "onde as pessoas se reúnem, se reconhecem umas às outras e, com isso, conhecem a si mesmas”. Por isso, não podemos atribuir somente uma dimensão física aos espaços, pois eles existem a partir dos discursos que os dizem e os veem; um espaço que também é imaginado, pois sua “natureza” física é inseparável da cultura que o compõe. Para Maffesoli (2004), esse mundo imaginado diz respeito "a fluxos afetivos, às manifestações estéticas, aos movimentos éticos, em suma, a toda esta órbita do sensível, do sensual, do colorido, do brilho do artificial, do dionisíaco [...]” (p. 58), marcando as experiências sociais do espaço vivido.

Maffesoli (2003, p. 56) constata que existe uma dificuldade em certos intelectuais para captarem “a parte de poesia de que é preenchido o cotidiano”. Poesia que, segundo o autor (2003, p. 56), certamente não é reivindicada como tal, mas que se encontra com força "nessas comunicações não verbais pelas quais se expressa a paixão social”. Certeau (1996, p. 183), por sua vez, afirma que uma "prática do espaço é indissolúvel do lugar sonhado", pois se trata de processo indefinido em que estamos ausentes, de passagem, mas sempre à procura daquilo que podemos viver, ainda que no plano das figurações oníricas.

As singulares visões de tais autores auxiliam nessa aproximação investigativa a certas experiências noturnas. Durante as observações, as cenas compostas pareciam adquirir a função de “altares” para as celebrações, aproximando os indivíduos entre si por meio das sensações e permitindo a articulação entre o vivido e o sentido. O rapaz, com sua performática leitura à beira 
do lago artificial, pretendia menos passar despercebido do que chamar a atenção e o olhar dos passantes. É exatamente nessa ação de parecer estar solitário em meio à multidão que os sentidos de seu corpo acionam e possibilitam essa interação com o lugar. Compostas pelos demais sujeitos, pela vegetação, sons, luzes, cores e cheiros, essas são experiências que podem ser entendidas “como um processo engajado de duração e movimento, articulado através de redes de sensações e por meio de panoramas de espaços, corpos e tempos” (ELLSWORTH, 2005, p. 29).

Ouvir o ritmo sonoro e movimentar o corpo em interação com a música executada em público produz a sensação de estar em meio aos outros em um lugar onde existe a possibilidade de se “sentir” seguro. A música ao vivo executada em espaços noturnos, além de amplamente utilizada como forma de atração notívaga, possui importância para as experiências de aprendizagem em que a relação com o outro está envolvida com deslocamento e movimentação no lugar. Segundo Tuan (1983), a música muda nossa direção do tempo e do espaço, pois o som rítmico, ao se sincronizar com o movimento do corpo, anula o sentido da finalidade de uma ação para alcançar um objetivo. Para o autor (1983), ao mudar o ambiente pela introdução de uma banda de música, objetivamente, a pessoa continua a caminhar “[...] aparentemente com o mesmo propósito” (p. 143). No entanto, segundo Tuan, subjetivamente, a força direcional do espaço-tempo diminui, abrindo outras possibilidades para interagir em um lugar, pois cada passo não é mais um simples movimento que conduz ao destino, mas sim para um espaço aberto e indiferenciado e onde "a ideia de um objetivo bem localizado perde relevância” (p.143).

A música, nesse sentido, age como invólucro sonoro que permite "embalar” as vivências em um lugar público noturno. Essa condição de “embalagem”, de “envelopamento” que o corpo adquire por meio das diferentes configurações do espaço-tempo em lugares noturnos nos aproxima do conceito de embodiment ${ }^{4}$, funcionando como a "incorporação" de todos os componentes presentes em um lugar, integrando movimentos e sensações em que não mais se separam corpo/mente, tempo/espaço, sujeito/objeto. O embodiment, segundo Ellsworth (2005), é o que permite uma experiência de aprendizagem se efetivar nessa relação de conhecimento do outro e do mundo por meio dos aspectos, tanto exteriores quanto aqueles que são interiorizados pelo sujeito. A sensação produzida através da música no evento noturno no parque permitia a abertura de um espaço-tempo em que o indivíduo aprendia na interação com o outro e com o lugar.

Maffesoli (2004) usa a expressão "ligância” social no sentido francês, como tudo "aquilo que me liga ao outro” (p.49), bem como sua significação inglesa, “que remete à confiança que podemos

\footnotetext{
${ }^{4}$ Embodiment também pode ser traduzido como “incorporado”, “encarnado” ou “personificado”. Neste texto, o termo conserva a grafia conforme consta em Ellsworth (2005).
} 
sentir nos outros, ou à confiança que experimento com terceiros diante de algo que nos é externo” (p. 49). Assim, continua o autor, “o meio, misto como é, seria condição de possibilidade da existência humana, a partir da existência social e da existência natural. Isso equivale a dizer que o ‘eu só toma consciência de si’ como relação” (p. 49). É dessa maneira que a audição e a visão acionadas pela música, pelas artes performáticas ou por demais práticas em que corpo/mente estão em funcionamento constante, produzem sensações que colocam em interação o indivíduo com os lugares em que se encontram.

Ellsworth (2005) considera as experiências vivenciadas como construtoras de sensações, pois o “corpo” dos ambientes pedagógicos encontra o corpo dos sujeitos por meio de redes de relações de interação. Em uma experiência de aprendizagem, em que aprendemos pela participação com os outros em um lugar, o corpo atua como estrutura orgânica da ação, onde o cérebro é o órgão que transmite estímulos em forma de pensamentos e a mente como a responsável pelas sensações durante essa ação pensada e realizada. Todo esse movimento é inseparável, produzido simultaneamente, pois, como afirma Ellsworth (2005, p.1), é a fusão do pensar-sentir, a "sensação encarnada de fazer sentido, a experiência vivida das nossas aprendizagens que fazem o que chamamos de conhecimento”. A atuação conjunta entre corpo/mente procura romper com o entendimento de que o indivíduo pensa, age e sente separadamente. Essa distinção é crucial para entender a centralidade do trabalho das sensações para a produção de experiências de aprendizagem, uma vez que o acionamento de todos os sentidos é o que permite ao sujeito se encontrar plenamente vivo e atuante nos lugares. Para Ellsworth (2005), a atuação do pensamento, das ações e dos sentimentos são componentes convidativos para vivenciar experiências, pois, ao se colocarem simultaneamente em suspensão e animação, produzem no sujeito "um intervalo de mudança, considerando uma pessoa que tem sido para uma em que ainda não se transformou” (p. 17).

\section{Cena 2 - Aproximações, contatos e afetos: POA me Faz Sorrir e os “abraços grátis”}

A nossa campanha se chama POA me Faz Sorrir e ela consiste em fazer com que as pessoas lembrem-se de momentos e lugares que já as fizeram sorrir em Porto Alegre e que Porto Alegre ainda tem chance de fazê-las sorrir novamente. [...] para que a gente possa mostrar para outras pessoas e talvez essas outras pessoas tenham a iniciativa de viver, de conhecer, de ir nesses lugares, de ter esperança de que Porto Alegre possa ser um lugar bom de novo 5 .

O depoimento destaca a campanha realizada por duas jovens durante o evento noturno no parque. Cartazes explicativos e adesivos entregues de mão em mão durante suas empolgadas

\footnotetext{
${ }^{5}$ Excerto de depoimento concedido por duas participantes do evento Serenata Iluminada. As informações foram captadas em equipamento audiovisual e posteriormente transcritas.
} 
explicações eram ações observadas por parte dos demais sujeitos que ali se encontravam. Aproximar pessoas através de lembranças pessoais positivas em busca da felicidade que teria se dissolvido em lugares públicos urbanos à noite: uma campanha que podia identificar outros modos de convivências noturnas como experiências produzidas pelas condições propiciadas naquele lugar. Experiências possíveis pela continuidade daquela ação, pelos contatos (quase) demorados dos corpos em encontros fortuitos com os demais sujeitos que também ocupavam o espaço-tempo público do parque durante aquele evento.

A entrega de um panfleto como possibilidade de aproximação, os olhares que se cruzavam, a fala e escuta atenta são ações que personificavam o intento das meninas para com seus abordados. Práticas realizadas através da interação que aquele lugar noturno possibilitava. "Porto Alegre está tão triste, conte pra nós um lugar que te faz feliz na cidade!”. Talvez a procura do "lugar feliz”, do lugar de felicidade proposto pelas meninas nunca fosse encontrado, porque ele já estava ali, presente naqueles encontros e sensações, embora fugazes e efêmeros. As "utopias” do lugar sonhado, a topologia desejada, estava no viver ativo de possibilidades e conhecimentos que podiam acontecer a cada encontro com os outros naquele parque. O lugar da felicidade buscada, imaginada e desejada, se realizava ali, onde cada aproximação, cada prática produzia experiências do encontro com o outro.

Segundo Ellsworth (2005), determinados lugares podem ser interpretados como ambientes que criam "topologias" de relacionamento entre eu e o outro, que colocam em movimento o “dentro" e o "fora”. Lugares que "nos convidam a habitar essas topologias de forma a liberar potencialidades para lançamentos de pensamentos, sentimentos e (inter)ações que em outras velhas configurações são capturadas e não são livres para emergir” (ELLSWORTH, 2005, p.117). Um convite que nos possibilita percorrer esse topos em busca das experiências a partir de outras e novas perspectivas que ampliam as possibilidades de operar com os usos e entendimentos do conceito de pedagogia no espaço-tempo urbano e noturno. Andar em segurança entre e com os outros em um espaço público e noturno impelia as falas das meninas, conduzia suas ações para um estar junto. Elas, as meninas, fabricavam sorrisos, possibilitavam encontros. Sensações de segurança, práticas de convivência pensadas e sentidas em que o corpo, a mente e o cérebro atuavam de forma simultânea e constante naquele lugar.

Durante a caminhada investigativa empreendida pelo parque, observo em diferentes grupos uma forma de intervenção urbana que tem se tornado bastante comum em lugares públicos da 


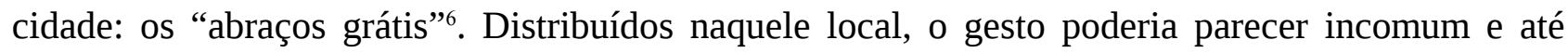
arriscado caso fosse executado durante outra noite no mesmo parque da cidade.

Os meninos dos “abraços grátis” também divulgavam sua intenção pelo parque por meio de um cartaz grafado à mão. Ação, segundo seus realizadores, usada como forma de demonstrar tanto seu descontentamento frente às tentativas de cercar com grades aquele espaço público quanto às constantes práticas violentas e de vandalismo realizados naquele lugar durante a noite. Tal prática, embora singular e instantânea, parecia assumir uma sutil forma de resistência frente à insegurança e ao medo que provocam o esvaziamento dos espaços públicos noturnos para o lazer, a diversão, as atividades laborais e quaisquer outras práticas sociais realizadas à noite. O contato por meio do abraço funcionava como iniciativa, expandindo-se criando um ambiente marcado pela vivência do toque, pela experiência de uma sensação tátil onde o corpo era receptivo, distanciando-se de condutas agressivas, espalhando afetos naquele espaço-tempo noturno. Na potência daquelas aproximações físicas, e "grátis”, parecia se anunciar o que Maffesoli (2004, p. 40) identifica como “característica da comunhão sensível ou afetiva que vem substituir a sociedade puramente utilitária”.

Na demora de um abraço, no instante de um encontro afetivo, no contato sensível, como tais experiências atravessam e permanecem no corpo do outro? O abraço mobiliza a aprendizagem do encontro; instaura o saber da procura pelo outro; interrompe, ainda que brevemente, o ritmo alucinante do espaço-tempo urbano. Na prática dos “abraços grátis” era preciso aprender a arte da espera e a espera era apre(e)ndida, pois seus realizadores estavam em um lugar que proporcionava o prolongamento dos instantes. Aprender a capturar os “instantes eternos”, como Maffesoli (2003, p. 61) chama esses intervalos de suspensão e interrupção do tempo em que saímos da "temporalidade racional e liberal que caracteriza a atividade diurna”. Os abraços possibilitavam atribuir àquela noite um espaço-tempo em que experiências produziam formas afetivas de condução pelo parque. Maffesoli acredita (2004) em experiências sociais em que repousa uma “razão sensível”, pois a sensibilidade deposita ênfase na vida e na experiência, mas também no banal e no cotidiano, acentuando e pluralizando as razões e as sensações. Para o autor (2004), é na fusão da experiência, da vivência e da coletividade que podemos encontrar o fundamento e a legitimidade da razão que entra em sinergia com o sensível. Os espaços e os tempos imaginados, sentidos e praticados estão repletos de vivências cotidianas, de experiências plurais que se fundem por meio do contato com o outro, pois "é essa

6 Freehugs ou “abraços grátis” é considerado um tipo de intervenção urbana e surgiu em Sidney, na Austrália, com um único indivíduo, conhecido como Juan Mann, que decidiu sair pelas ruas, oferecendo abraços a pessoas desconhecidas em lugares públicos, usando um cartaz de papelão nas mãos com a mensagem “freehugs” (GUSCHIKEN; MARTINS, 2012). 
experiência do outro, a experiência de sua vivência através da minha que fundamenta a compreensão dos diferentes ‘mundos’ constitutivos de um dado período” (MAFFESOLI, 2004, p. 42).

\section{Cena 3 - Trocas sociais: o artesanato como "saber-fazer pessoal"}

Aproximo-me de um rapaz que vende suas "cachaças artesanais". Observo que ele explica para os demais em sua volta sobre os produtos utilizados e o processo de fabricação. Não foi preciso questionar sobre os possíveis "lucros" daquelas vendas, pois, segundo ele, o que proporciona $e$ motiva sua ação são encontros como o evento Serenata Iluminada, onde a reunião de pessoas com objetivos comuns cria um ambiente propício para a divulgação da importância de produtos artesanais (Noturnos de Campo).

Em minha caminhada pelo parque, percebi em alguns pontos do lugar uma singular comercialização de bebidas, alimentos e outros produtos fabricados artesanalmente. Alguns vendedores ambulantes, devido à quantidade de pessoas reunidas, expunham e ofereciam seus produtos, mas aquele encontro proporcionava outras modalidades de artesanato e um tipo diferente de artesão. Em sua maioria eram jovens, prováveis estudantes que se dedicavam durante seu tempo livre à produção artesanal de bebidas e comidas. O lucro, ou qualquer outro motivo para se manter financeiramente nessa etapa de suas vidas, não era o principal objetivo desses “artesãos”. Cachaças, cervejas, café e outras bebidas e comidas eram expostas durante o encontro noturno no parque, evidenciando uma produção artesanal em que as habilidades de cunho "pessoal” ou "artesanal” assumiam preponderância, distanciando-se dos produtos industrializados e comercializados em outros lugares públicos.

Sarlo (2014), em sua obra A Cidade Vista: Mercadorias e Cultura Urbana, pode auxiliar nessa discussão que busca mostrar como determinadas práticas artesanais são vividas como experiências em que os sujeitos aprendem formas de convívios em comum pela noite. Ao observar os ambulantes espalhados pelos espaços públicos de Buenos Aires, Argentina, Sarlo (2014, p. 39) destaca uma classificação entre aqueles que se dedicam aos produtos industriais e aqueles produtos em que “o carregado, o disforme e o irregular evocam 'o feito à mão””. Em um mundo de objetos idênticos fabricados por máquinas, a autora (2014) sublinha que as irregularidades provam a singularidade do artesanato, atestam os saberes de seus realizadores e as qualidades daquilo que “leva a marca de uma mão”.

Certeau (1996) afirma que desde que o conceito de "popular” foi inscrito para identificar uma hierarquização entre o trabalho científico e industrial sobre a produção que não tem por finalidade exclusiva o lucro, baseando-se, assim, por outros modelos socioeconômicos, certas práticas e 
saberes têm sido relegados à “marginalidade” social. O autor (1998) lembra-nos de que, embora identificadas dentro do campo social onde se exerçam, as práticas ordinárias remetem àqueles procedimentos multiformes, a ações que fogem aos cursos estabelecidos pelo cotidiano, escapando dos fluxos diários urbanos, levando a outros entendimentos e percepções do espaço e do tempo vivido e instaurando uma inquietante familiaridade com a cidade.

Nesse sentido, Certeau (1996) aproxima-se de Sarlo (2014) ao considerar as práticas produzidas de forma artesanal como uma “arte” que subverte a força da economia contemporânea e foge da lógica industrial, de tempo e fins lucrativos, pois suas táticas populares tanto desviam para seus fins próprios a “ordem efetiva das coisas” (p. 88) quanto instituem um “saber-fazer pessoal”. Práticas artesanais que tanto podem ser exploradas por um poder econômico dominante como simplesmente negadas por um discurso ideológico (CERTEAU, 1996). Durante o evento noturno no parque, as produções artesanais eram representadas como uma arte, insinuando um "estilo" de invenções técnicas, de resistência moral, de trocas sociais. Para Certeau (1996, p.88), essa arte pode ser definida como "uma estética de golpes (de operações de artista) e uma ética da tenacidade (mil maneiras de negar a ordem estabelecida o estatuto da lei, de sentido ou de fatalidade)”.

Essas “práticas desviacionistas”, denominadas assim pelo autor (1996), estão articuladas com as condições dos lugares em que são realizadas, pois se configuram como formas de escambo, em que seus realizadores não são apenas produtores ou fazedores de objetos para formas de consumo caracterizados pelas leis de mercado contemporâneas. Para Certeau (1986), tais práticas são como invenções de outros modos estratégicos de relacionamentos, pois sua produção é considerada como um componente cultural, em que a ordem é representada por meio de “trocas”, “invenções” e “resistências”. As perspectivas de Certeau (1996) e Sarlo (2014) expandem nossa compreensão a respeito de práticas artesanais, possibilitando entendê-las como outras "economias”, como trocas que vão muito além de comercialização, como experiências que reverberam outros modos de vivência e interação social.

Articuladas às condições do lugar em que são realizadas, as práticas artesanais observadas no encontro Serenata Iluminada funcionam como experiências vividas tanto pelos "fazeres” da produção e da troca de manufaturas, quanto pelos “saberes” que vão além da comercialização, constituindo-se como trocas sociais em um lugar noturno. O que essas trocas movimentam são experiências nas quais a comunicação, a reciprocidade, a amizade e outras relações que possibilitam vínculos sociais em um lugar são aprendidas através da interação entre os sujeitos e as condições no espaço-tempo do lugar em que estão inseridos. 
Se por um lado as trocas artesanais exibiam naquele lugar sua própria materialidade, exteriorizada por meio dos objetos, artefatos e práticas de escambo, por outro, é possível encontrar em tais ações a produção de outras experiências. Ao oferecer seus produtos artesanais, o rapaz apresentando nesta cena noturna repassava aos demais participantes do evento não só os seus conhecimentos de fabricação, mas também aprendia a conviver de outros modos no lugar. O artesanato se inseriu naquele espaço-tempo como outra economia, em que as moedas de troca eram as relações recíprocas em um lugar que é vivido, sentido e praticado.

\section{Considerações Finais}

O que possuem em comum as cenas compostas a partir da observação ao evento Serenata Iluminada no Parque Farroupilha? A música executada ao vivo, os “abraços-grátis”, a campanha POA me Faz Sorrir, as trocas artesanais ou mesmo um participante que traz para a rua a possibilidade de realizar em público uma atividade privada como a leitura de um livro são ações que funcionam como iniciativas criativas, utilizando intervenções como convite para a população ocupar os espaços-tempos públicos da cidade. São ações imprescindíveis para encontros, expressões de afeto, convívios e demais experiências sentidas em comum pelas quais a percepção dos participantes está em interação com espaço-tempo de um lugar público e noturno. Experiências sensíveis que dão visibilidade a pedagogias em um parque público, pois estão engajadas com a materialidade do lugar, potencializando os conhecimentos, práticas e sensações. Ellsworth (2005) salienta que "se a pedagogia consiste de práticas e processos que transformam qualitativamente os modos como pensamos e atuamos no mundo, isso também transforma qualitativamente nossa incorporação no e do mundo” (p.118).

Na coletividade, na busca da interação, da comunhão, os ocupantes do encontro noturno Serenata Iluminada aprendem outras formas de relação consigo e com o outro por meio da transitoriedade dos espaços-tempos de um parque à noite. As amizades, as trocas, os encontros, a música e as demais interações instauram a potência dos convívios afetivos, do que é sentido e praticado, produzindo experiências nas quais os participantes aprendem a conviver em um lugar público notório pela insegurança à noite. Nas experiências de seus participantes, o parque adquire outros sentidos, diferindo da "violência” e do “medo" muitas vezes presentes em lugares públicos. Abraços, toques, gestos, olhares, vozes, movimentam corpo, cérebro e mente para a produção de práticas e a ativação de sentidos que em momentos diurnos dificilmente seriam vividos da mesma forma. 
As experiências vividas durante o evento Serenata Iluminada são impraticáveis durante as demais noites em que o Parque Farroupilha assume a condição de lugar intransitável para a grande maioria da população e propício para roubos, assaltos e outras violências. Se por um lado a reocupação de espaços públicos fortalece e possibilita vínculos de identificação coletiva entre seus frequentadores, por outro, as questões de insegurança em uma cidade onde o medo do outro e do desconhecido assumem destaque, instauram outros modos de condução dos sujeitos na noite. É preciso lembrar que, em lugares noturnos urbanos, onde a constante sensação de insegurança e de medo exige a incessante e renovada aprendizagem da proteção, e até mesmo da sobrevivência, outras pedagogias são colocadas em funcionamento na noite.

Colocar-se diante do mundo e dos outros está indubitavelmente ligado com distintos modos pedagógicos em que tanto somos conduzidos como conduzimos nossas práticas, ações, sentimentos e pensamentos. Pedagogias que nos direcionam, conduzem-nos pelos espaços físicos da arquitetura de uma cidade, pelas condições expressivas e específicas de determinados lugares. Exterioridades indispensáveis para a produção de nossas experiências subjetivas, dobras pedagógicas que capacitam nossa percepção para múltiplas interações com o mundo por meio dos sentidos. Essas experiências de se colocar e ser colocado diante dos outros e do mundo aumentam a capacidade de sentirmos e agirmos em comum nos espaços-tempos públicos, encontrando articulações com outros modos de condução na noite.

Diante de tal reflexão, é importante esclarecer que as pedagogias da noite apresentadas neste texto são configuradas nas especificidades dos espaços-tempos noturnos investigados na cidade de Porto Alegre. Sua produção e funcionamento encontram-se indubitavelmente articulados às condições e características dos lugares noturnos selecionados e analisados, bem como às práticas realizadas pelos sujeitos nesses lugares. Assim, o desafio de dar visibilidade a pedagogias atuantes durante um evento noturno somente tornou-se possível através da identificação das experiências vividas tanto pelas relações dos sujeitos entre si, quanto pelas sensações proporcionadas em um parque público urbano à noite.

\section{Referências}

ALMEIDA, Maria Isabel Mendes de; TRACY, Kátia Maria de Almeida. Noites nômades: espaço e subjetividade nas culturas jovens contemporâneas. Rio de Janeiro: Rocco, 2003.

BAUER, M. W \& AARTS, B. A construção do corpus: um princípio para a coleta de dados qualitativos. In: M. W. Bauer; G. Gaskell, (Eds.). Pesquisa qualitativa com texto, imagem e som: um manual prático (pp 39-63). Tradução P. A. Guareschi. 12 ed. Petrópolis, Vozes, 2014. 
BENJAMIN, Walter. Magia e técnica, arte e política: ensaios sobre literatura e história da cultura. Tradução de Sérgio Paulo Ruanet; Prefácio Jeane Marie Gagnebin. 8. ed. rev. São Paulo: Brasiliense, 2012. (Obras Escolhidas v. 1).

CAMOZZATO, V. C. \& COSTA, M. V. Vontade de pedagogia - pluralização de pedagogias e condução de sujeitos. Cadernos de Educação (UFPel), Pelotas, n.44, p.22-44, 2013. Disponível: <https://periodicos.ufpel.edu.br/ojs2/index.php/caduc/article/view/2737>.

CANEVACCI, M. Sincretika Explorações Etnográficas Sobre Arte Contemporânea. $1^{\circ}$ ed. São Paulo: Studio Nobel, 2013.

CERTEAU, M; GIARD, L.; MAYOL, P.. A Invenção do Cotidiano - 1. Artes de Fazer. Tradução de Ephraim F. Alves e Lúcia Endlich Orth. 3. ed. Petrópolis: Vozes, 1996.

DELEUZE, Gilles. Francis Bacon: lógica das sensações. Tradução de Silvio Ferraz e Annita Costa Malufe. Paris: éditions de la diference, 1981.

DUARTE JUNIOR, J. O sentido dos sentidos. A educação (do) sensível. Curitiba: Criar Edições Ltda, 2001.

ELLSWORTH, E. Places of Learning: media, architecture, pedagogy. London; New York: Routledge, 2009.

GIROUX, H.\& MCLAREN, P. Por uma pedagogia crítica da representação. In: T. T. Silva \& A. F. Moreira (Eds.) Territórios Contestados: o currículo e os novos mapas políticos e culturais (pp. 144-158). Petrópolis, RJ: Vozes, 1995.

GOTTSCHALK, S. Postmodern Sensibilities and Ethnographic Possibilities. In: A. Banks; S. P. Banks (Eds.), (pp. 205-234). London/New Delhi : Altamira Press. (Ethnografic Alternatives, v. 4), 1998.

GUSHIKEN, Y. \& MARTINS, F. G. P. FreeHugs: Dinâmicas de troca, dádiva e estranhamento na intervenção urbana. Comunicação, mídia e consumo. 24,179-198, 2012.

GWIAZDZINSKI, L. A condição noturna. In: Colaboratória, Grupo Interdisciplinar. Manifesto da Noite. Grupo Interdisciplinar Colaboratória. São Paulo: Invisíveis Produções, 2014.

HARVEY, D. O espaço como palavra-chave. GEOgraphia, 28, 8-39, 2012. Disponível em: <http://www.geographia.uff.br/index.php/geographia/article/view/551/345>. Acesso em: 21 de mai. de 2020.

LARROSA BONDIA, J. Notas sobre a experiência e o saber da experiência. Revista Brasileira de Educação, 2002. 19, 28, Campinas. Disponível em: <http://www.scielo.br/pdf/rbedu/n19/n19a02.pdf>. Acesso em: 15 de maio de 2020.

LOCKE, John. Ensaio acerca do entendimento humano. Tradução de Anoar Aixex. São Paulo: Ed. Nova Cultural, 1999.

LORITE GARCÍA, N. La observación casual: uma proposta para el estúdio de las transformaciones sócio-mediáticas. Encontro Internacional de Investigadores de la Comunicacion, Chile, 2000.

MAFFESOLI, M. O Instante Eterno. O retorno do trágico nas sociedades pós-modernas. Tradução de Rogério de Azevedo e Alexandre Dias. São Paulo: Zouk, 2003.

. Notas sobre a pós-modernidade: o lugar faz o elo. Atlântica Editora: Rio de Janeiro, 2004. 
No Fundo das Aparências. Tradução de Bertha Halpern Gurovitz. 4. ed. Petrópolis, RJ: Vozes, 2010.

MARGULIS, M. et al. La Cultura de la Noche: la vida noturna de los jóvenes en Buenos Aires. Buenos Aires: Biblos, 2005.

SARLO, B. A cidade Vista: mercadorias e cultura urbana. 1. ed. São Paulo: WMF Martin Fontes.(Coleção Cidades), 2014.

SENNETT, R. (1988). O Declínio do Homem Público: as tiranias da intimidade. Tradução de Lygia Araújo Watanabe. São Paulo: Companhia das Letras.

WATKINS, Megan, NOBLE, Greg, DRISCOLL Catherine. Pedagogy - the unsaid of socio-cultural theory. In: WATKINS, Megan, NOBLE, Greg, DRISCOLL Catherine (eds). Cultural Pedagogy and Human Conduct. London: Routledge, 2015.

Recebido em: 15/06/2020

Aprovado em: 26/11/2020 